\title{
Energy states in superlattices connected with incommensurate phase presence
}

\author{
D.M.Bercha ${ }^{1,2}$, K.E.Glukhov ${ }^{1}$, L. Yu. Kharkhalis ${ }^{1}$ \\ 1 Institute of Solid State Physics and Chemistry, \\ Uzhgorod National University \\ 54 Voloshina Str., 88000 Uzhgorod, Ukraine \\ 2 Institute of Physics, Pedagogical University, \\ 16a Rejtana Str., 35-310 Rzeszów, Poland
}

Received October 24, 2002, in final form April 16, 2003

The electron behavior in incommensurate phase in $\mathrm{Sn}_{2} \mathrm{P}_{2} \mathrm{Se}_{6}$ has been considered as the motion in the Mathieu potential. A simple model of effective potential change under a transition incommensurate - domain-like structure has been proposed. A behavior of the obtained localized levels system versus the model parameters has been investigated.

Key words: modulated structures, Mathieu crystal, incommensurate, ferroelectrics

PACS: $64.70 . R h$

\section{Introduction}

The modulated structures have attracted a lot of attention of the investigators in recent decades due to the variety and uncommonness of their physical properties. It has been found that such structures can appear, in particular, in ferroelectrics [1-3] being in the so-called incommensurate phase. This phase is connected with a recurrent change in the order parameter along some preferential direction. The period of the modulation wave is incommensurate with the magnitude of lattice parameter. So, for instance, in well investigated $\mathrm{Sn}_{2} \mathrm{P}_{2} \mathrm{Se}_{6}$ ferroelectrics, the parameters of which were used for our modulation (see table 1), the modulation with the wave vector $q$ takes place over the temperature range $T=193-221 \mathrm{~K}$. With good accuracy it should be considered that this vector is directed along [001] and its magnitude corresponds to the wave with the period which makes up 12-14 unit cell periods [4].

The existence of the preferential direction results in the reduction of the dimen-

*E-mail: glukhov@mail.uzhgorod.ua 
Table 1. Parameters of $\mathrm{Sn}_{2} \mathrm{P}_{2} \mathrm{Se}_{6}$ used in the modelling.

\begin{tabular}{|c|c|c|c|c|}
\hline & $m^{*} / m_{0}$ & $V, \mathrm{eV}$ & $L / c, \AA$ & $c, \AA$ \\
\hline c-band & 0.1 & $0.1-0.2$ & $12-14$ & 6.85 \\
\cline { 1 - 2 } v-band & 0.8 & & & \\
\hline
\end{tabular}

sionality of the problem that allows one to consider the carrier flow as the motion in the corresponding one-dimensional potential. It should also be noted that the $\mathrm{Sn}_{2} \mathrm{P}_{2} \mathrm{Se}_{6}$ ferroelectrics have a comparatively wide energy gap $\left(\mathrm{E}_{\mathrm{g} 0} \sim 1.85 \mathrm{eV}[5]\right)$. Thus, the investigated herein transport properties are mainly related to the photoexcited nonequilibrium charge carriers.

Let us consider the next peculiarity of the problem. The incommensurability between the periods of the lattice and the modulation wave results in the loss of the translation invariance of the system. This does not make it possible to treat the energy structure of this system by usual methods. Many works devoted to physical and mathematical investigations of the given problem have appeared [6-8] (see also references in [2]). In [7], the loss of the translation invariance is compensated by involving the additional dimension that leads to the complex clusterized structure of the energy spectrum [8]. In such a method based on the symmetrical approach of the modulation the potential magnitude is not taken into consideration. However, the estimation of this quantity based on the known values of the deformation potentials and the amplitude of the oscillations of the order parameter for $\mathrm{Sn}_{2} \mathrm{P}_{2} \mathrm{Se}_{6}$ shows that in comparison with the magnitude of the lattice field the modulating potential can be considered as a small perturbation $(4 V \sim 0.5 \mathrm{eV})$. Generally speaking, the electron properties can be predicted or interpreted correctly if the complete energy structure of the current carriers is known. But, because of a low level of the carrier occupation, it is possible to take into account only the vicinities of the spectrum extrema points instead of accounting the complete band structure. Therefore, the definite conclusions concerning the carrier motion can be made within the framework of the effective mass approximation. This approximation can be used in case of a weak change in the perturbation potential amplitude within the unit cell of the initial crystal similarly to the case under consideration.

\section{Model}

At a further modelling, we will take into account the modulation magnitude of the band edges $(V)$ being the same both for electrons and for holes (see figure 1 )

In the employed approximation the motion of the charge carriers is determined by the following one-particle Schrödinger equation:

$$
\left\{-\frac{\hbar^{2}}{2 m^{*}} \partial_{z}^{2}+W+2 V \cos \left(\frac{2 \pi z}{L}\right)\right\} \psi(z)=E \psi(z),
$$




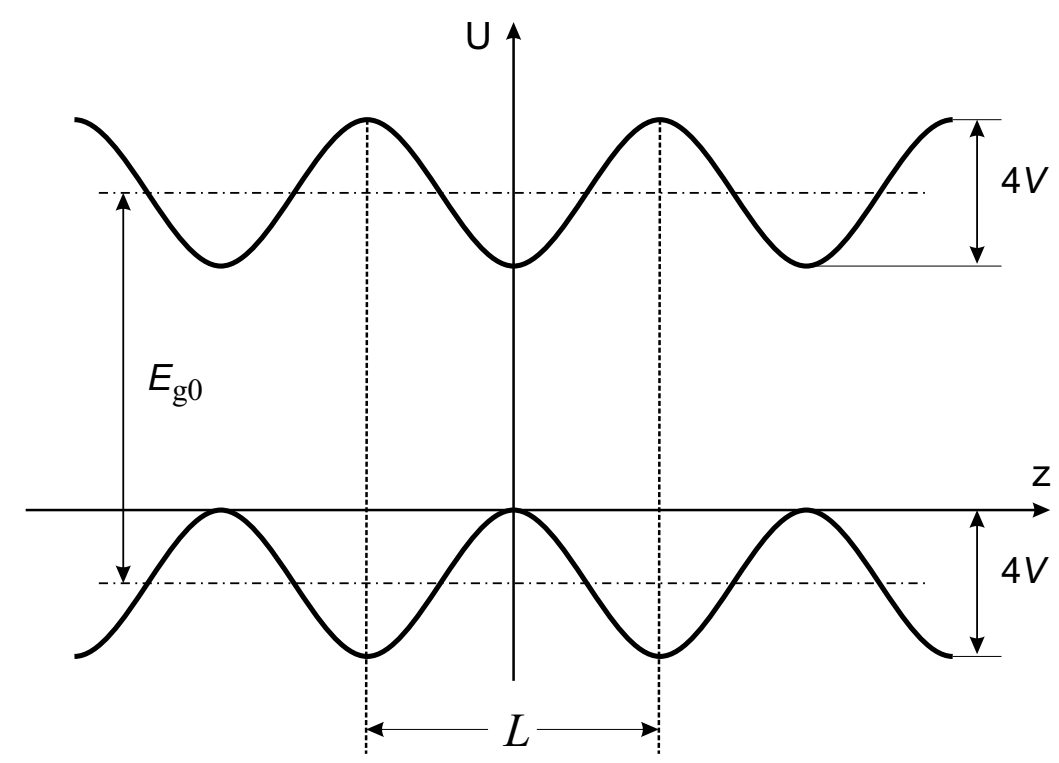

Figure 1. Sketch of the modulated edges of the c- and v-bands.

where $L$ is the length of the modulation wave, $m^{*}$ is the effective mass of the carriers in the band under consideration and $W$ indicates the c- and v-bands edges without the modulation $\left(W_{\mathrm{e}}=E_{\mathrm{g} 0}-2 V, W_{\mathrm{h}}=-2 V\right)$. This equation with the harmonic potential can be reduced to a well known equation for the functions of the elliptical cylinder, also referred to as Mathieu functions [9]. For this purpose, we will introduce a new variable $\xi=\pi z / L$

$$
\left\{-\frac{\hbar^{2}}{2 m^{*}} \frac{\pi^{2}}{L^{2}} \partial_{\xi}^{2}+W+2 V \cos (2 \xi)\right\} \psi(\xi)=E \psi(\xi) .
$$

Then, we will divide (2) by the coefficient at the derivative. It gives:

$$
\left\{\partial_{\xi}^{2}+\frac{2 L^{2} m^{*}}{\pi^{2} \hbar^{2}}(E-W)-2 \frac{2 L^{2} m^{*}}{\pi^{2} \hbar^{2}} V \cos (2 \xi)\right\} \psi(\xi)=0 .
$$

Introducing the parameters

$$
\epsilon=\frac{2 L^{2} m^{*}}{\pi^{2} \hbar^{2}}(E-W), \quad q=\frac{2 L^{2} m^{*}}{\pi^{2} \hbar^{2}} V
$$

we reduce (3) to the following form

$$
\left\{\partial_{\xi}^{2}+\epsilon-2 q \cos (2 \xi)\right\} \psi(\xi)=0
$$

which exactly coincides with the above mentioned equation for the Mathieu functions. Since the space period of the potential in the equation (1) is equal to $L$, we will be interested only in $\pi$-periodical solutions of the equation (5). It should also be noted that because of the invariance of the expression in the brackets under space inversion, the solutions will possess the definite parity. 
Table 2. Energies of several first levels obtained for electrons $\left(E_{\mathrm{e}}\right)$ and holes $\left(E_{\mathrm{h}}\right)$ in the cosine-like potential with parameters of $\operatorname{Sn}_{2} \mathrm{P}_{2} \mathrm{Se}_{6}(L=12 \mathrm{c}, V=0.1 \mathrm{eV})$.

\begin{tabular}{|c|c|c|c|c|}
\hline & $S_{1}$ & $A_{1}$ & $S_{2}$ & $A_{2}$ \\
\hline$E_{\mathrm{e}}, \mathrm{eV}$ & -0.204 & 0.169 & 0.366 & 0.922 \\
\hline$E_{\mathrm{h}}, \mathrm{eV}$ & -0.327 & -0.184 & -0.049 & 0.076 \\
\hline
\end{tabular}

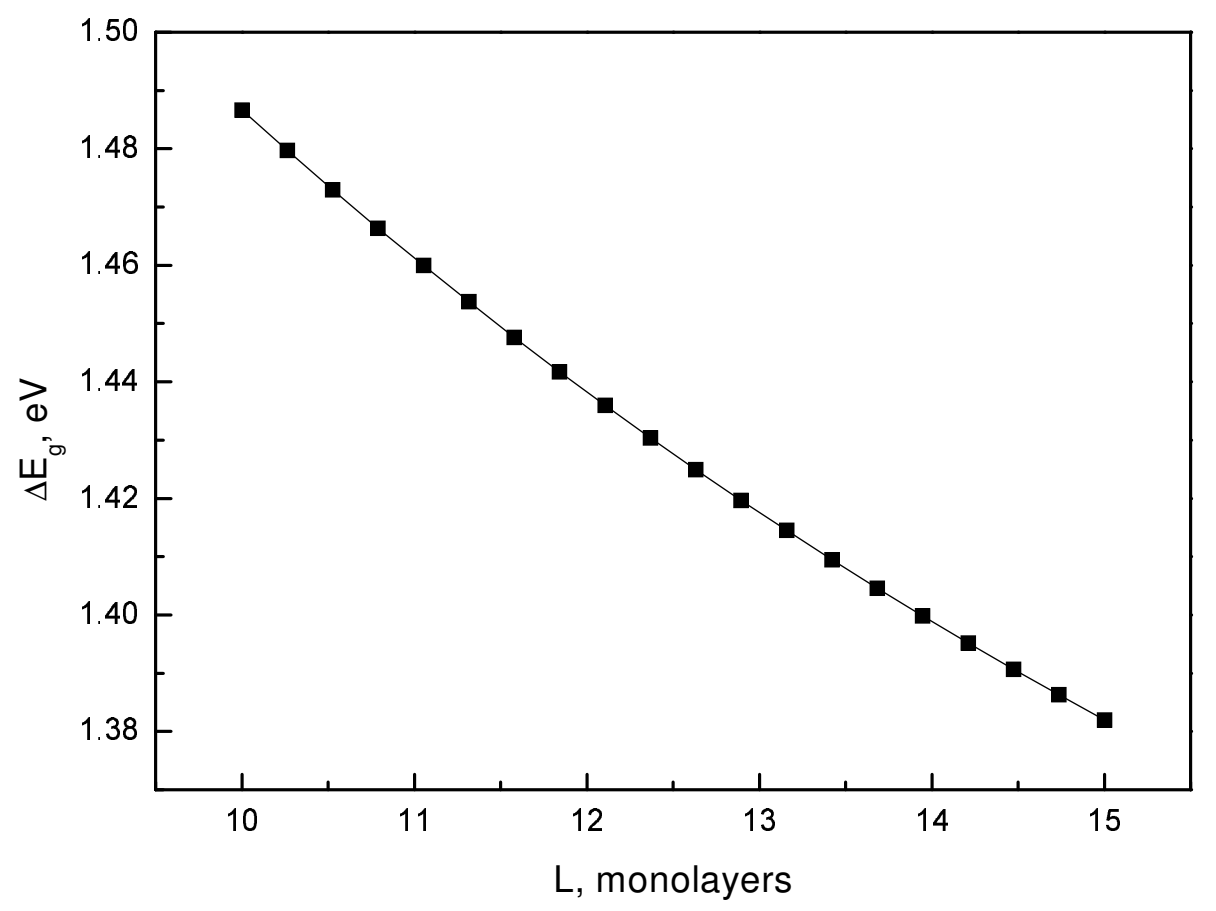

Figure 2. Calculated dependence of the energy gap $E_{\mathrm{g}}$ versus the modulation wavelength in $\mathrm{Sn}_{2} \mathrm{P}_{2} \mathrm{Se}_{6}$.

Several first values of the energy obtained for even $(S)$ and odd $(A)$ states of the electrons and holes for the parameters of $\mathrm{Sn}_{2} \mathrm{P}_{2} \mathrm{Se}_{6}$ are presented in table 2 .

Since the amplitude of the wave vector of the modulation with the change of temperature varies at the invariable direction of this vector (see figure 1.7 in [4]), the dependence of the energies of the dimensional quantization levels versus the modulation wave period can be obtained.

The energy gap dependence of modulation wavelength calculated within the framework of the described model is presented in figure 2. Here, under $E_{\mathrm{g}}$ we understand the minimal distance between localized levels of electrons and holes $\left(E_{\mathrm{g}}=E_{\mathrm{e}}-E_{\mathrm{h}}+E_{\mathrm{g} 0}\right)$.

However, it should be noted that the approximation used does not take into account the admixing of the higher-order modes to the simple periodical potential from (1). These modes can essentially distort the profile of the potential in the vicinity of the phase transition temperature with the tendency to form wide potential barriers, corresponding to the domains which are separated by narrow wells i.e. 
Table 3. Boundary values of parameters used in the modelling of transition from modulated to domain-like structure.

\begin{tabular}{|c|c|c|}
\hline & $f_{1}$ & $f_{2}$ \\
\hline$\lambda / c$ & 12 & 5 \\
\hline$\Lambda / c$ & 0 & $10^{5}$ \\
\hline$V, \mathrm{eV}$ & 0.8 & 0.1 \\
\hline$W, \mathrm{eV}$ & 0.4 & 0.1 \\
\hline
\end{tabular}

domain walls. Therefore, it is of interest to study the dynamics of the above obtained localized levels at the transition into the ferroelectric phase. For this purpose one can use the model permitting to obtain a smooth transition of the modulated potentials with the temperature decrease. The similarity between the problem under study and that of determining the miniband spectrum of the superlattices allows one to employ the matrix formalism of the envelope function method. The essence of this method is formulated as follows. The two row vector-solution including the envelope function and its first derivative has been considered. By using the socalled transfer and interface matrix [10], the solution is transferred through the period of the investigated system and then Bloch theorem is taken into account. This makes it possible to determine the carrier dispersion. It should be noted that this method was initially formulated for the piecewise-constant potential used in the well-known Kronig-Penney model. But, by way of several modifications [11], one can make it suitable for the arbitrary smooth potential. Turning to the modelling of the transition from a harmonic profile of the potential to the potential in the form of narrow wells separated by wide barriers one can propose the following model:

$$
U_{\theta}(z)= \begin{cases}V(\theta) \cos \left(\frac{2 \pi z}{\lambda(\theta)}\right)+W(\theta), & z \in[0, \lambda(\theta)] ; \\ V(\theta)+W(\theta), & z \in[\lambda(\theta), \lambda(\theta)+\Lambda(\theta)],\end{cases}
$$

where the magnitude $\theta \in[0,1]$ is the parameter of the transition, the values $\lambda, \Lambda, V$ and $W$ which determine the widths of the wells, barriers and their depth and height, accordingly, are chosen in the form of the linear in $\theta$ functions:

$$
f=f_{1}+\theta\left(f_{2}-f_{1}\right)
$$

Here, $f_{i}$ denotes the boundary values of the $f=\lambda, \Lambda, V, W ; i=1$ corresponds to the modulated structures and $i=2$ corresponds to the domain structure.

The schematic profile of the potential (6) for the parameters presented in table 3 is shown in figure 3 .

\section{Discussion}

Returning to the proposed model let us emphasize that $\theta=0$ corresponds to the modulated structure while $\theta=1$ corresponds to the domain structure. From the 

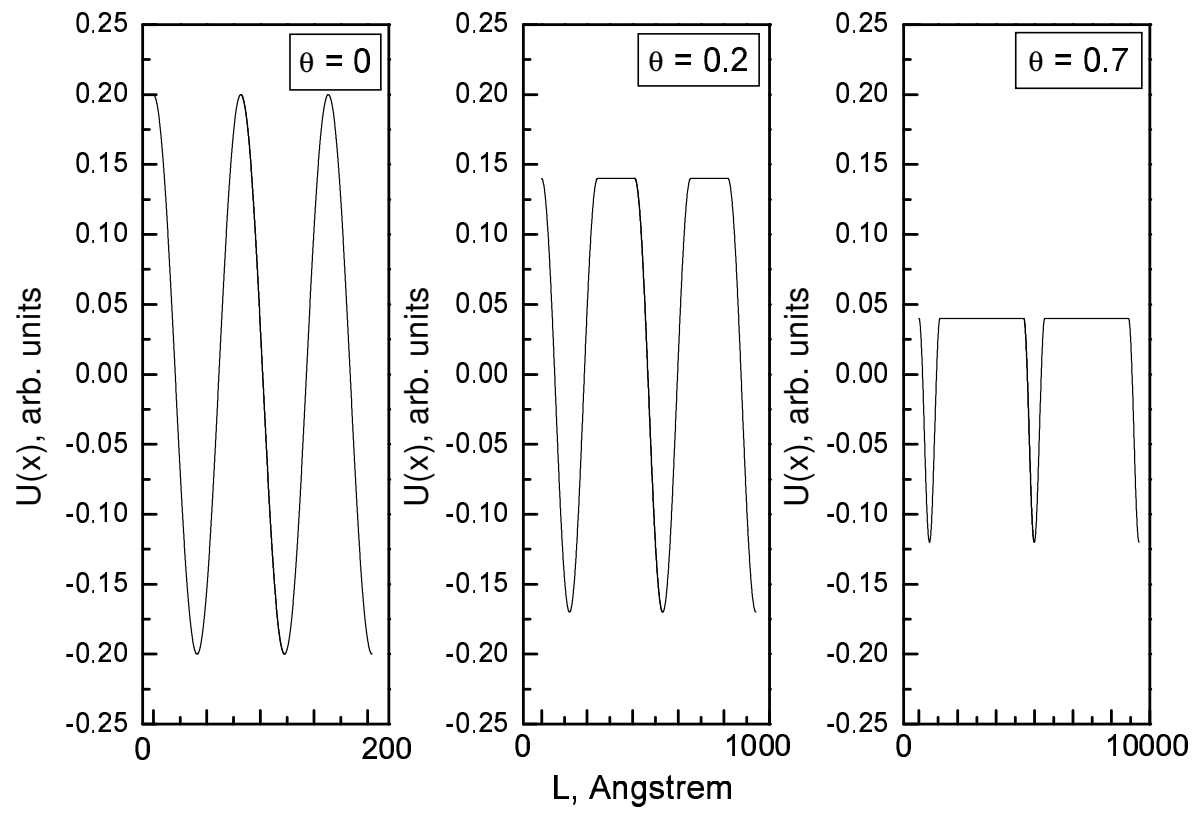

Figure 3. The illustration to the potential transformation of the change in $\theta$ parameter.

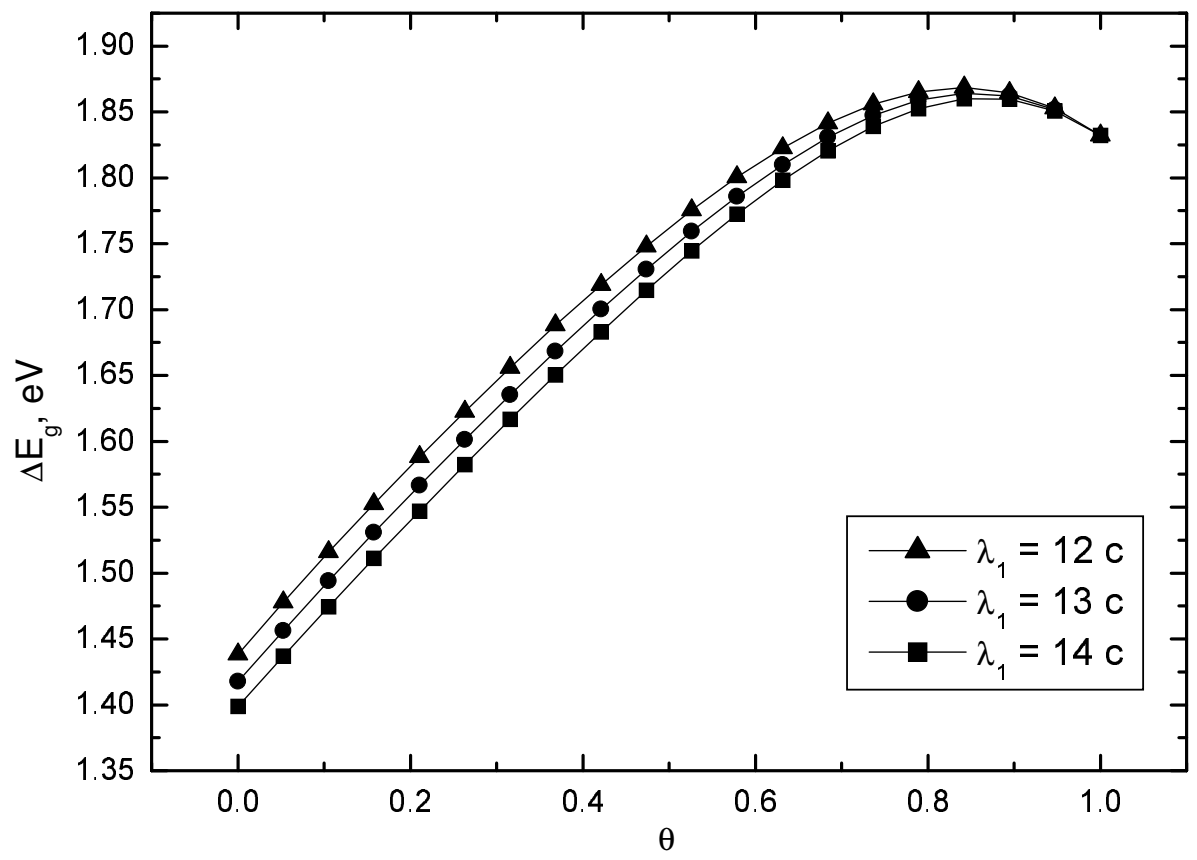

Figure 4. $E_{\mathrm{g}}$ versus $\theta$ for the parameters whose boundary values are presented in table 3. 
obtained dependencies (see figure 4) of the energy gap versus the introduced parameter one can see that localized states become shallow at approaching the domain-like potential. This fact can be easily explained from the general quantum-mechanical point of view. Indeed, the $\theta$ value increase leads to such a transformation of the potential under which the wells become narrow and separated one from another by wide barriers. This obviously results in the levels lift. However, we have to note that there is a converse tendency in our model. Namely, the behavior of the energy shift $W(\theta)$ can produce the lowering of the localized levels system obtained. Taking into account the presence of these two opposite tendencies we can explain the maxima in the calculated dependencies $E_{\mathrm{g}}(\theta)$. Such a peculiarity possibly appears due to the choice of the linear in $\theta$ behavior adopted for all considered parameters. Nevertheless, one can state that the proposed model is capable of quite good qualitative description of the considered transition and can be used as the first step approximation of electron subsystem behavior in modulated structures.

The quantum effects obtained can lead to an unusual behavior of several kinetic and optical properties, namely to the realization of the dark conductivity according to Mott's law in $\mathrm{Sn}_{2} \mathrm{P}_{2} \mathrm{~S}_{6}$, the memory effect in incommensurate phase in the $\mathrm{Sn}_{2} \mathrm{P}_{2} \mathrm{Se}_{6}$ crystal [12], the phenomenon of a long-time photoconductivity relaxation [13], an unusual behavior of the optical absorption edge in the ferroelectric and incommensurate phase. Really, the redistribution of the charge carriers on the created energy levels and the abrupt growth of the density of electron states that lead to the intensification of the electron inhomogeneity are possible. The similar situation is realized in the system with electron-phonon interaction in the quantizing magnetic field [14].

\section{References}

1. Levanyuk A.P., Sannikov D.G. Theory of phase transitions in ferroelectrics with creation of superstructure incommensurate to initial period. // Fiz. Tverd. Tela, 1976, vol. 18, No. 2, p. 423-428 (in Russian).

2. Warczewski J. Krysztaliczne Structury Modulowane. Wydawnictwo Naukowe PWN, Warszawa, 1993 (in Polish).

3. Parasmajan T.K., Hasanov S.S., Shehtman V.Sh. et al. Incommensurate phase in proper ferroelectric $\mathrm{Sn}_{2} \mathrm{P}_{2} \mathrm{Se}_{6}$. // Fiz. Tverd. Tela, 1985, vol. 27, No. 11, p. 3327-3331 (in Russian).

4. Vysochanskii Yu.M., Slivka V.Yu. Ferroelectrics of $\mathrm{Sn}_{2} \mathrm{P}_{2} \mathrm{Se}_{6}$ Family. Properties in Vicinity of the Lifshitz Point. Lviv, 1994 (in Russian).

5. Bercha D.M., Grabar A.A., Kharkhalis L.Yu., Mitin O.B., Bercha A.I. Band spectrum and model of prastructure of $\mathrm{Sn}_{2} \mathrm{P}_{2} \mathrm{~S}_{6}$ crystal. // Fiz. Tverd. Tela, 1997, vol. 39, No. 7, p. $1219-1222$.

6. Janssen T., Janner A. Superspace groups and representations of ordinary space groups: alternative approuches to the symmetry of incommensurate crystal phases. // Physica, 1984, vol. 126A, p. 163.

7. de Wolff P.M. Symmetry operations for displacively modulated structures. // Acta Cryst., 1977, vol. 33, No. 3, p. 493-497. 
8. Bell S.C., Stinchombe R.B. Hierarchical clustering in the spectra of incommensurate systems. // Jour. Phys. A: Math. Gen., 1989, vol. 22, p. 717-729.

9. Janke E., Emde F. Table of Functions with Formulae and Curves. New York, 1969.

10. Gashimzade N.F., Ivchenko E.L. Boundary conditions and electron effective mass in superlattice. // Fiz. Tekh. Polup., 1991, vol. 25, p. 323 (in Russian).

11. Glukhov K.E., Bercha D.M. Accounting of the boundary region influence on energy structure of the short-period symmetrical and asymmetrical superlattices $(\mathrm{GaAs})_{N} /(\mathrm{AlAs})_{M}$ in the envelope function approximation. (to be published).

12. Jamet J.P., Lederer P. Observation of a new memory effect in a modulation structure. // J. Phys. Lett., 1983, vol. 44, No. 7, p. 257-264.

13. Bercha A.I., Bercha D.M., Grabar A.A., Mitin O.B., Kharkhalis L.Yu. - In: XXIV International School Physics of Semiconducting Compounds, Jaszowiec, 1991.

14. Kochelap V.A., Sokolov V.N., Vengalis B.Yu. Phase Transitions in Semiconductors With Deformational Electron-phonon Interaction. Kiev, Naukova Dumka, 1984 (in Russian).

\title{
Енергетичні стани у надґратках пов'язані 3 наявністю несумірної фази
}

\author{
Д.М.Берча ${ }^{1,2}$, К.Є.Глухов ${ }^{1}$, Л.Ю.Хархаліс ${ }^{1}$ \\ 1 Інститут фізики та хімії твердого тіла, \\ Ужгородський національний університет \\ 88000 Ужгород, вул. Волошина, 54 \\ 2 Інститут фізики, Педагогічний університет, \\ Польща, 35-310 Ряшів, вул. Рейтана, 16а
}

Отримано 24 жовтня 2002 р., в остаточному вигляді 16 квітня 2003 р.

Розглянуто поведінку електронів у несумірній фазі $\mathrm{Sn}_{2} \mathrm{P}_{2} \mathrm{Se}_{6}$ як рух у Мат'є потенціалі. Запропоновано просту модель зміни ефективного потенціалу при переході від несумірної до доменоподібної структури. Отримано систему локалізованих рівнів та досліджено ії поведінку в залежності від параметрів моделі.

Ключові слова: модульовані структури, Мат'є кристал, несумірність, сегнетоелектрики

PACS: $64.70 . R h$ 